\title{
Modification of Chitin Particles with Ionic Liquids Containing Ethyl Substituent in a Cation
}

\author{
Malgorzata M. Jaworska, ${ }^{1}$ Andrzej Górak, ${ }^{2,3}$ and Joanna Zdunek ${ }^{4}$ \\ ${ }^{1}$ Faculty of Chemical and Process Engineering, Warsaw University of Technology, Ul. Warynskiego 1, 00-645 Warsaw, Poland \\ ${ }^{2}$ Faculty of Biochemical and Chemical Engineering, TU Dortmund University, Emil-Figge-Straße 70, 44227 Dortmund, Germany \\ ${ }^{3}$ Faculty of Process and Environmental Engineering, Lodz University of Technology, Ul. Wólczańska 213, 90-924 Lódź, Poland \\ ${ }^{4}$ Faculty of Material Science, Warsaw University of Technology, Ul. Wołoska 141, 02-507 Warsaw, Poland
}

Correspondence should be addressed to Malgorzata M. Jaworska; jaworska@ichip.pw.edu.pl

Received 21 February 2017; Revised 25 April 2017; Accepted 2 May 2017; Published 31 May 2017

Academic Editor: Santiago Garcia-Granda

Copyright (c) 2017 Malgorzata M. Jaworska et al. This is an open access article distributed under the Creative Commons Attribution License, which permits unrestricted use, distribution, and reproduction in any medium, provided the original work is properly cited.

\begin{abstract}
Chitin cannot be dissolved in conventional solvents due to the strong inter- and intrasheet network of hydrogen bonds and the large number of crystalline regions. Some ionic liquids (ILs) have been suggested in the literature as possible solvents for chitin. Seven of them, all having an ethyl group as substituent in the cationic ring, have been tested in this work: [Emim] [Cl], [Emim][Br], [Emim][I], [Emim][OAc], [Emim][Lact], [Epyr][I], and [EMS][BFSI]. Chitin was insoluble in [EMS][BFSI] while for all other ILs solubility was limited due to high viscosity of solutions and equilibria have not been reached. Changes in physical structure, particle size distribution, and crystallinity of recovered chitin depended on ionic liquid used. Increase in porosity was observed for chitin treated with $[\mathrm{Emim}][\mathrm{Cl}],[\mathrm{Emim}][\mathrm{I}],[\mathrm{Emim}][\mathrm{Br}]$, and $[\mathrm{Emim}][\mathrm{Lact}]$; changes in particle size distribution were observed for $[\mathrm{Emim}][\mathrm{AcOH}]$ and $[\mathrm{EMS}][\mathrm{BFSI}]$; increase in crystallinity was noticed for chitin treated with [Epyr][I] while decrease in crystallinity for [Emim][I] was noticed. All tested ionic liquids were reused four times and changes in FTIR spectra could be observed for each IL.
\end{abstract}

\section{Introduction}

Chitin, a poly $\mathrm{N}$-acetylglucosamine, is a nontoxic, natural biopolymer that has not found wide industrial application due to its chemical resistance. This property can be also regarded as advantageous when we search for a new carrier for enzymes. It is chemically, mechanically, and thermally stable but its particles are flat, often rectangular, and nonporous. The structure of chitin particles should be modified to get more porous particles or particles with more expanded external surfaces that will give an increase in the specific surface area and increase in the number of possible linkage sites. The changes in particle structure can be achieved by a dissolution/precipitation process using one of the complex solvents such as $\mathrm{LiCl} /$ dimethylacetamide, concentrated (16\%) cold (around $0^{\circ} \mathrm{C}$ ) $\mathrm{NaOH}$ solution, or $\mathrm{CaCl}_{2} \cdot \mathrm{H}_{2} \mathrm{O}$ saturated methanol, to obtain amorphous chitin. But it should be emphasized that nearly all these solvents are toxic, corrosive, and not environmentally friendly; they often cause polymer chain degradation and cannot be recovered and reused. Recently ionic liquids (ILs) have been investigated as new solvents for chitin. Although ionic liquids are not as "green" as they were previously thought, they can be regenerated and reused several times, which would decrease their environmental impact significantly.

It has been reported that [Emim] [OAc] (1-ethyl-3-methyl imidazolium acetate) and [Emim][Cl] (1-ethyl-3-methyl imidazolium chloride) [1-3] are good solvents for chitin. The highest chitin solubility was reported from $3.5 \% \mathrm{w} / \mathrm{w}$ in [Emim] [Cl] to 20\% w/w in [Emim][OAc] [2]. Such high solubility was useful for preparation chitin yards (by spinning or electrospinning) [4-6], preparation of scaffolds for stem cells [7], chitin composites with other biopolymers $[6,8,9]$, surface modification to create particles with expanded external surfaces [3], or systems creation for water or $\mathrm{CO}_{2}$ capture [10]. In all cases chloride or acetic anion was used as the counterion for the $[$ Emim] cation. 
Such good solubility of chitin turned our attention to ionic liquids containing ethyl substitution in a cation. As the general aim of our investigation was to find an ionic liquid that would be able to modify the structure or surface of chitin particles in a simple way, we have tested several ionic liquids containing ethyl substituents. In our investigations 5 commercially available ionic liquids containing an ethyl substituent in the imidazolium ring (1-ethyl-3-methyl imidazolium, [Emim]) and 1 in a pyridinium ring (1-ethylpyridinium, [Epyr]) have been investigated. As anion, the halides (chloride $[\mathrm{Cl}]$, bromide $[\mathrm{Br}]$, and iodide $[\mathrm{I}]$ ) and organic acids (acetic [OAc], lactic [Lact]) were used. In this way we investigated the influence of halide anion $([\mathrm{Emim}][\mathrm{Cl}],[\mathrm{Emim}][\mathrm{Br}]$, $[$ Emim $][\mathrm{I}])$; organic anion $([$ Emim $][\mathrm{OAc}],[$ Emim $][$ Lact $])$; type of a ring in a cation ([Emim][I], [Epyr][I]). Additionally di-ethyl-methylsulphonium bis(trifluoromethyl sulfonyl)imide ([EMS][BFSI]) was also used. Among the ionic liquids examined only two, ([Emim] [OAc] and [Emim] $[\mathrm{Cl}])$, have been reported in the literature as suitable for chitin modification, while the effectiveness of the other five examined is reported on for the first time in this work.

Our investigations focused on solubility of chitin in ionic liquids, changes in structure of chitin particles observed under electron microscope (SEM), changes in particle size distribution (Laser Diffraction Particle Size Analyzer), changes in crystallinity (XRD) of chitin, and the reusability of ionic liquids for chitin dissolution observed as changes in FTIR spectrum.

\section{Materials and Methods}

2.1. Chemicals. $\alpha$-Chitin from shrimp (BioLog Heppe, Germany) with acetylation degree $\mathrm{AD}=96 \%$ (according to declaration of the producer) was used in experiments. Chitin was not additionally purified before use. Particles were ground and a fraction of $25-50 \mu \mathrm{m}$ was used in all experiments.

1-ethyl-3-methyl-imidazolium chloride ([Emim][Cl]) was kindly donated by Merck KGaA. 1-Ethyl-3-methyl-imidazolium lactate ([Emim][Lact]) was purchased from Aldrich. 1-Ethyl-3-methyl-imidazolium acetate ([Emim][OAc]), 1ethyl-3-methyl-imidazolium bromide ([Emim][Br]), 1-ethyl3-methyl-imidazolium iodide ([Emim][I]), 1-ethylpyridinium iodide ([Epyr][I]), and di-ethyl-methylsulphonium bis(trifluoromethyl sulfonyl)imide ([EMS][BFSI]) were purchased from Iolitech (Germany).

All chemicals, including ethanol and water, were of analytical grade.

\subsection{Experimental}

2.2.1. Solubility of Chitin in IL. Ionic liquid (approx. 1.0-1.5 g) was weighed into test tube, heated $\left(105^{\circ} \mathrm{C}\right)$, and mixed $(200 \mathrm{rpm})$ and a small portion $(0,005-0,010 \mathrm{~g})$ of chitin was added. Samples were left until complete dissolution of chitin (24-48 h) was observed; then the next portion of chitin was added. This scheme was repeated as long as the added chitin dissolved in the ionic liquid. Dissolution was assessed visually and under light microscope where transparent solution was expected, Figure 1.
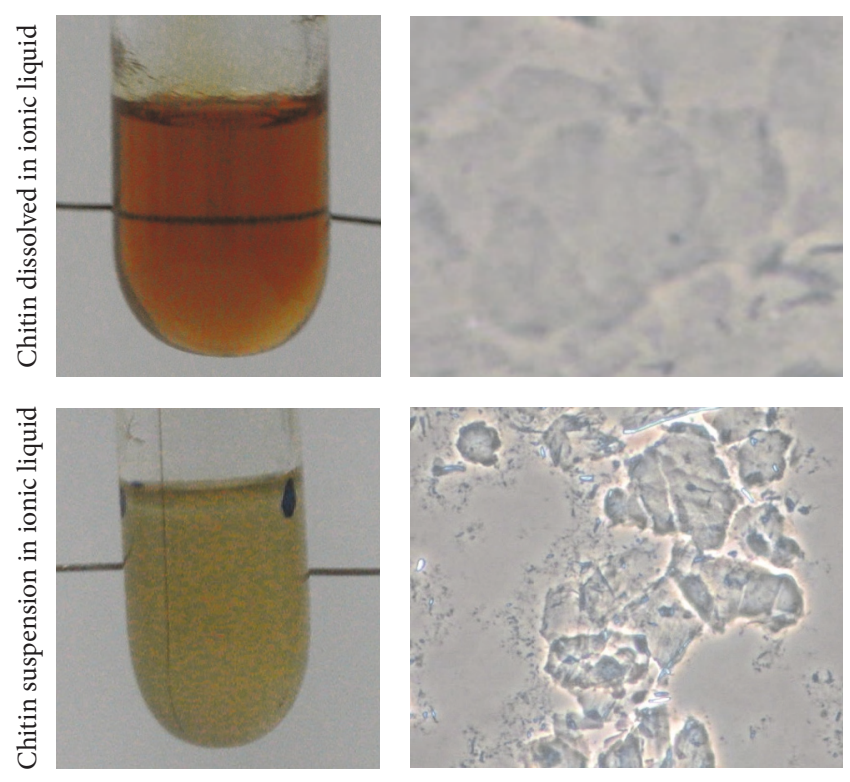

FIGURE 1: Dissolution of chitin in ionic liquid has been assessed visually and under light microscope.

2.2.2. Modification of Chitin Particles with Ionic Liquids. The ionic liquid (approx. $2.0 \mathrm{~g}$ ) was weighed to two test tube and then chitin $(5 \% \mathrm{w} / \mathrm{w})$ was added. Samples were incubated in an oil bath at $105^{\circ} \mathrm{C}$ and mixed $(200 \mathrm{rpm})$ for $48 \mathrm{~h}$. Then chitin was regenerated with water. Chitin solution in ionic liquid (except [Epyr][I]) was transferred to a syringe and added dropwise (manually) to $10 \mathrm{~mL}$ hot $\left(90^{\circ} \mathrm{C}\right)$ water mixed at high speed $(500 \mathrm{rpm})$. Chitin solution in [Epyr][I] solidified and the polymer was recovered by adding $5 \mathrm{~mL}$ of hot water $\left(90^{\circ} \mathrm{C}\right)$ to the test tube at vortex mixer. Chitin particles were washed 5-7 times with ethanol and then 3-5 times with water and lyophilized.

2.2.3. Reuse of Ionic Liquid. All solutions recovered from washing the chitin were collected in a biker (separate for each IL) and dried by lyophilization. The recovered ionic liquid was than reused in the same way as described above (Section 2.2.2). Each ionic liquid was used four times.

\subsection{Analytical Methods}

2.3.1. Electron Microscopy. A Nikon ELWD 03/OD75 Electron Microscope was used for the SEM observations and photographs of samples that had been lyophilized and sprayed with gold particles.

2.3.2. Particle Size Distribution. The particle size distribution $\left(d_{10 \%}-d_{90 \%}\right)$ and mean size of particles $\left(d_{\text {mean }}\right)$ were evaluated using a Laser Diffraction Particle Size Analyzer LS 13,320, Universal Liquid Module (Coulter-Beckman, USA), a mean value of 3 samples being taken. The standard deviation of $d_{\text {mean }}$ as well as the particle size distribution $\left(d_{10 \%}-d_{90 \%}\right)$ was lower than $10 \%$. 
2.3.3. Crystallinity of Chitin Particles. The X-ray diffraction patterns were determined using Bruker D8 Advance diffractometer with DaVinci system, equipped with LFF 2,2 kW Cu lamp. The voltage was $40 \mathrm{kV}$ and the intensity $40 \mathrm{~mA}$. The $2 \Theta$ angle was scanned between $3^{\circ}$ and $60^{\circ}$, and the counting time was $2 \mathrm{~s}$ per step $\left(\Delta 2 \Theta\right.$ was $\left.0.05^{\circ}\right)$; the patterns were collected using the LYNXEYE strip detector. In order to compare the crystallinity of the samples the following calculations were made based on the XRD patterns obtained between $3^{\circ}$ and $60^{\circ}(2 \theta)$. The percentage crystallinity $\left(X_{C}\right)$ was determined using the following equation:

$$
X_{C}(\%)=\frac{\sum A_{C}}{\sum A_{C}+\sum A_{A}} \times 100 \%,
$$

where $\Sigma A_{C}+\sum A_{A}$ give the sum of the area under all the phases crystalline and amorphous peaks and $\Sigma A_{C}$ yields the sum of the areas under the crystalline peaks present in the scan range between $3^{\circ}$ and $60^{\circ}$ and $A_{A}$ is the value for the amorphous phase.

2.3.4. FTIR Spectra. FTIR spectra were obtained using a Thermo Scientific Nicolet 6700 FTIR Spectrophotometer. The ionic liquids were measured directly. All scans were carried out from $4000 \mathrm{~cm}^{-1}$ to $400 \mathrm{~cm}^{-1}$ with a resolution of $6 \mathrm{~cm}^{-1}$ as the mean of 32 scans.

FTIR spectra of chitin (after each series) were measured as $13 \mathrm{~mm}$ discs with $\mathrm{KBr}$ ( $1 \mathrm{mg}: 200 \mathrm{mg}$ ). All scans were taken using the same apparatus in the range of wavelengths $4000-400 \mathrm{~cm}^{-1}$ with a resolution of $6 \mathrm{~cm}^{-1}$. Mean of 32 scans was presented as a result.

\section{Results}

Seven ionic liquids were tested as solvents for chitin, with the assumption that most of them would be able to modify particle size, structure, or crystallinity of the chitin particles. In the first part of our work the solubility of chitin in ILs was tested. In the next part the influence of ILs on chitin particle morphology and reuse of ionic liquids was investigated.

Each sample of ionic liquid was used 4 times ( $1 \mathrm{~s}, 2 \mathrm{~s}, 3 \mathrm{~s}$, and $4 \mathrm{~s}$ ), where each series consisted of dissolution of chitin in ionic liquid, regeneration with water, washing out of chitin with ethanol, washing out of chitin with water (washing liquids were collected), and evaporation of ethanol/water from ionic liquid. Next ionic liquid was used again for dissolution of chitin (next series of experiment). It was expected that chitin would dissolve in ionic liquids that could break or weaken hydrogen bonds stabilizing the chitin particle. We also expected that during precipitation with water new links among polymer chains could be created so particles with different size or structure should be created.

3.1. Solubility of Chitin in ILs. The solubilities of chitin in the ionic liquids tested are presented in Table 1 . The solubility was assessed on the basis of transparency of sample (visual and light microscope observations).

All ionic liquids tested, except [EMS][BFSI], were good solvents for chitin. The highest solubility was obtained for
[Emim] $[\mathrm{Br}]$ and $[$ Emim] $][\mathrm{I}]$ suggesting that ILs with large halide anions are better than those having a $[\mathrm{Cl}]$ anion. The result obtained for [Emim] $[\mathrm{Cl}]$ is in agreement with literature data [2]. High solubility was also measured for ionic liquids with organic anions. The chitin solubility measured for [Emim][OAc] was lower than the maximum value reported in the literature $(20 \%,[2])$, but the phase equilibrium could not be reached due to mixing problems (too high viscosity of the solution, mixing bar was not able to rotate). The result for [Emim] [Lact] was nearly as good as for [Emim] [OAc] but solution in [Emim][Lact] was less viscous than the latter one (visual observations). It means that [Emim][Lact] is probably more suitable for industrial applications as it allows for higher chitin solubility at lower viscosity. Such solutions are much easier to handle than other ILs with much higher viscosity (like with [Emim][OAc] or [Emim][Br] and [Emim][I]).

It was interesting to notice that on changing the cation from imidazolium ([Emim][I]) to pyridinium ([Epyr][I]), quite different phase behavior was observed. Chitin solution in [Emim] [I] at a concentration of $11 \%$ was still a liquid while chitin solution in [Epyr][I] solidified at a much lower concentration (5\%). Such behavior was not observed for any other tested ionic liquid. It should be also mentioned that chitin was practically insoluble in [EMS][BFSI], as a solubility lower than $1 \% \mathrm{w} / \mathrm{w}$ was observed.

For each chitin sample, after recovery, FTIR spectra were examined to check presence of ionic liquids. The washing out of ILs from chitin samples was confirmed by comparison of spectra of recovered and untreated chitin; no changes in chitin spectra were detected.

3.2. Particle Morphology. The influence of ILs on recovered particle morphology was investigated through SEM observations. Chitin was regenerated from ionic liquid solution by dropwise addition to water. Typical changes are presented, Figure 2.

Four different types of changes of chitin particle morphology have been observed: increase in porosity $([\mathrm{Emim}][\mathrm{Cl}]$, $[$ Emim][I], [Emim][Br], and [Emim][Lact]), increase in surface corrugation ([Emim][Lact], [Epyr][I]), formation of agglomerates ([Emim][OAc]), and decomposition ([EMS][BFSI]).

The intensity of observed changes was also influenced by the number of regeneration cycles undergone by the IL. For $[$ Emim] $[\mathrm{Cl}]$ and [Emim] [Lact] increase in porosity was similar for all series, but changes after the $1 \mathrm{~s}$ treatment with [Emim] [Cl] looked more like single "dots" while after the $4 \mathrm{~s}$ treatment it looked more like a "torn" structure, while in the case of [Emim][Lact] in all series "dot" changes were observed. It was also interesting to notice that for [Emim] [Br] changes were observed only for $1 \mathrm{~s}$ and $2 \mathrm{~s}$ series ("dot" like) while for [Emim][I] similar changes appeared only for $3 \mathrm{~s}$ and $4 \mathrm{~s}$. As a new portion of chitin was used in every series, the observed changes in polymer structure could be caused by an increase or decrease in the ability of the IL to break interand intrasheet $\mathrm{H}$-bonds, but the "strength" of interaction was not sufficient to destroy these bonds completely. 
TABLE 1: Solubility of chitin in ionic liquids $(\% \mathrm{w} / \mathrm{w})$ at $105^{\circ} \mathrm{C}$.

\begin{tabular}{lcccccc}
\hline$[$ Emim $][\mathrm{OAc}]$ & {$[$ Emim $][\mathrm{Lact}]$} & {$[\mathrm{Emim}][\mathrm{Cl}]$} & {$[\mathrm{Emim}][\mathrm{Br}]$} & {$[\mathrm{Emim}][\mathrm{I}]$} & {$[\mathrm{Epyr}][\mathrm{I}]$} & {$[\mathrm{EMS}][\mathrm{BFSI}]$} \\
\hline $9^{(1)}$ & 8 & 3 & $12^{(1)}$ & $11^{(1)}$ & $6^{(2)}$ & $<1$ \\
\hline
\end{tabular}

${ }^{(1)}$ Solution was transparent, but equilibrium concentration of chitin in IL could not be reached due to very high viscosity of the solution. ${ }^{(2)}$ Solution solidified at this concentration of chitin. Increase in porosity: $[$ Emim $][$ Lact $],[$ Emim $][\mathrm{Cl}]$,
$[$ Emim $][$ Br] $[$ Emim] $][\mathrm{I}]$
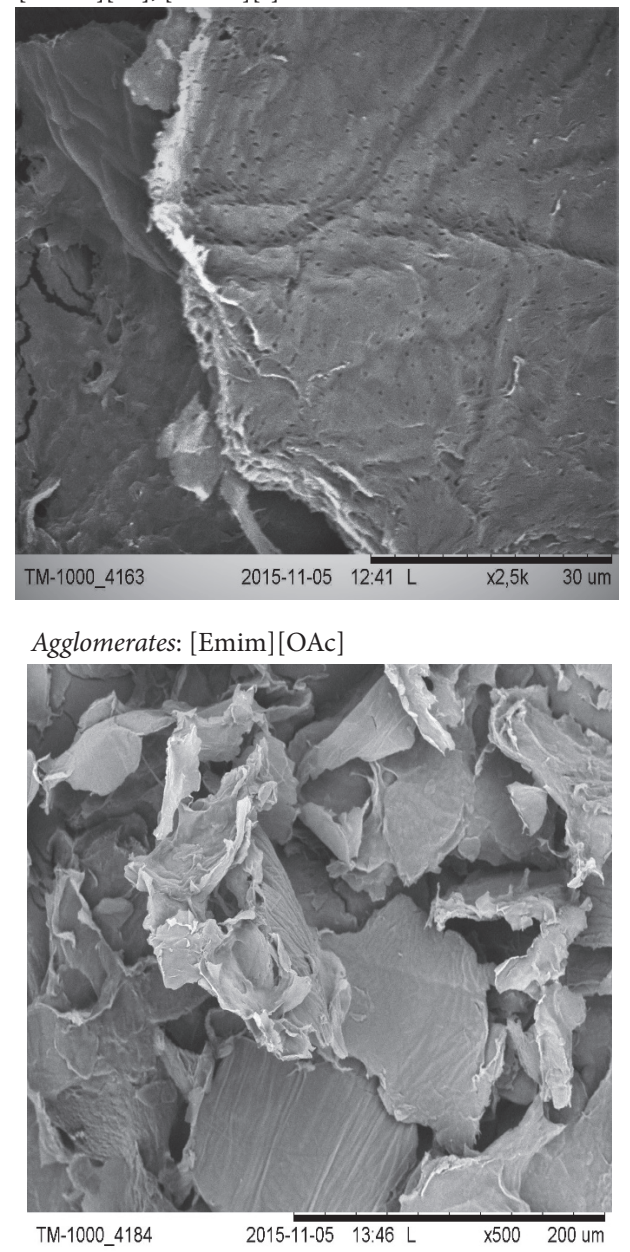

Increase in surface corrugation: [Emim][Lact], [Epyr][I]

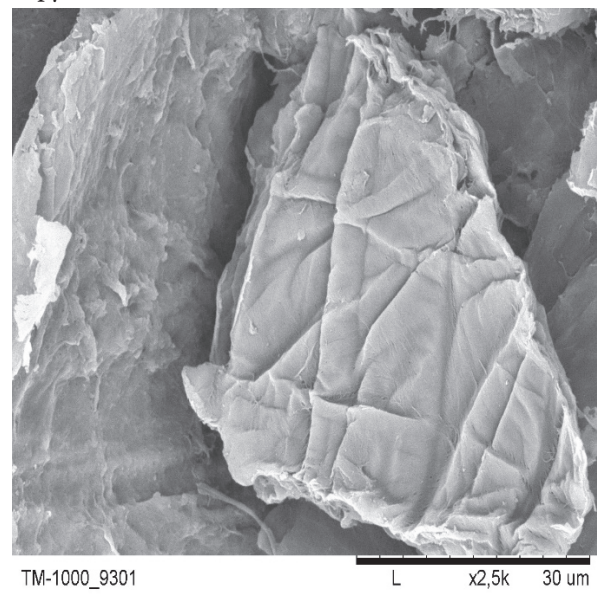

Decomposition: [EMS][BFSI]

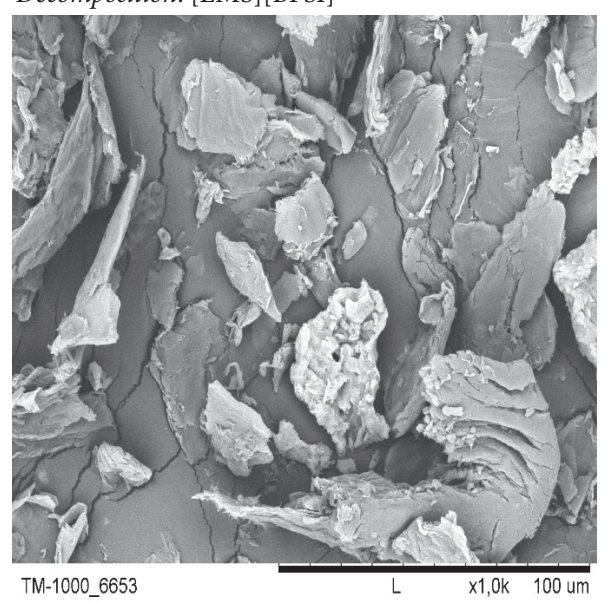

FIGURE 2: Typical changes in structure of regenerated chitin particles.

Rather than increasing porosity, [Emim][Lact] and [Epyr][I] caused an increase in surface corrugation. The surface of untreated chitin is smooth and with rare, single pores while particles treated with these ionic liquids showed a change in corrugation of the biopolymer surface.

[Emim][OAc] was the only ionic liquid able to create agglomerates. This IL was able to completely destroy the $\mathrm{H}$ bonding of chitin particles, and when solution was mixed with water new $\mathrm{H}$-bonds were created, so agglomerates were obtained instead of flat, rectangular-shaped particles. When the experiment was repeated with lower chitin concentrations (3\%, data not shown), regular particles in the shape of beads were obtained.

[EMS][BFSI] was also able to destroy the H-bonding; however it did not dissolve the chitin particles but an increase in the number of small particles was observed under SEM. The interaction between chitin and this IL caused degradation of chitin particles that was especially pronounced for $3 \mathrm{~s}$ and $4 \mathrm{~s}$ where as well as particle size degradation (see Table 1) changes in the surface (cracks at the surface) were observed.

3.3. Particle Size Distribution. Ionic liquids can not only change the structure of chitin particles but also influence the particle size. Mean value $\left(d_{\text {mean }}\right)$ and particle size distribution $\left(d_{10 \%}-d_{90 \%}\right)$ for particles recovered from ionic liquids able to modify their size are compared in Table 2.

It was found that only two ionic liquids ([Emim][OAc] and $[\mathrm{EMS}][\mathrm{BFSI}])$ were able to modify the size of polymer particles. [Emim][OAc] causes generation of agglomerates after precipitation of chitin with water. We postulate that 
TABLE 2: Mean size of chitin particles and particle size distribution.

\begin{tabular}{|c|c|c|c|c|}
\hline & $\begin{array}{c}1 \mathrm{~s} \\
d_{10 \%}-d_{90 \%} \\
\left(d_{\text {maen }}\right) \\
{[\mu \mathrm{m}]} \\
\end{array}$ & $\begin{array}{c}2 \mathrm{~s} \\
d_{10 \%}-d_{90 \%} \\
\left(d_{\text {maen }}\right) \\
{[\mu \mathrm{m}]}\end{array}$ & $\begin{array}{c}3 \mathrm{~s} \\
d_{10 \%}-d_{90 \%} \\
\left(d_{\text {maen }}\right) \\
{[\mu \mathrm{m}]}\end{array}$ & $\begin{array}{c}4 \mathrm{~s} \\
d_{10 \%}-d_{90 \%} \\
\left(d_{\text {maen }}\right) \\
{[\mu \mathrm{m}]}\end{array}$ \\
\hline Untreated chitin & & & & \\
\hline$[\mathrm{Emim}][\mathrm{OAc}]$ & $\begin{array}{c}82-1432 \\
(594)\end{array}$ & $\begin{array}{c}33-261 \\
(137)\end{array}$ & $\begin{array}{c}23-157 \\
(86)\end{array}$ & $\begin{array}{c}24-170 \\
(92)\end{array}$ \\
\hline [EMS][BFSI] & $\begin{array}{c}22-136 \\
(75)\end{array}$ & $\begin{array}{c}15-119 \\
(62)\end{array}$ & $\begin{array}{c}12-105 \\
(52)\end{array}$ & $\begin{array}{c}16-104 \\
(57)\end{array}$ \\
\hline
\end{tabular}

$\mathrm{SD}<10 \%$ for $d_{\text {mean }}, d_{10 \%}$, and $d_{90 \%}$.

TABLE 3: Crystallinity of chitin particles.

\begin{tabular}{lcc}
\hline sample & $\begin{array}{c}\text { Crystalline phase (1 s) } \\
{[\%]}\end{array}$ & $\begin{array}{c}\text { Crystalline phase (4 s) } \\
{[\%]}\end{array}$ \\
\hline $\begin{array}{l}\text { Untreated chitin } \\
\text { [Emim][OAc] }\end{array}$ & 97.8 & 92,6 \\
[Emim][Lact] & 84.6 & 86.4 \\
[Emim][Cl] & 83.8 & 85.3 \\
[Emim][Br] & 81.5 & 84.0 \\
[Emim][I] & 80.9 & 86.4 \\
[Epyr][I] & 100 & 87.1 \\
[EMS][BFSI] & 95.3 & 78.1 \\
\hline
\end{tabular}

during the dissolution process this ionic liquid completely destroys the hydrogen bonds that stabilize the chitin particle and chitin chains create new hydrogen bonds during the regeneration process. Unfortunately, this effect decreased in each series and for $4 \mathrm{~s}$ the size of the particles was close to that of untreated chitin. Contrary to this the ionic liquid [EMS][BFSI] causes decreasing particle size and, interestingly, this effect increased with each series. As chitin was not dissolved in this IL, the decrease in particle size was caused by their degradation, not by formation of new agglomerates as in the case of [Emim] [OAc].

For all other tested ionic liquids no significant changes in particle size distribution were observed. It means that the dissolution process was rather a gelation of chitin particles than real dissolution, because only slight changes (in the range of analytical error) in particle size were observed.

3.4. Crystallinity of Regenerated Chitin Particles. The crystallinity is a complex concept integrating the effects on the XRD of crystal strain, diffraction domain size, and crystal defects. The changes in crystallinity of chitin particles due to regeneration with water are presented in Figure 3 and in Table 3.

All the regenerated chitin samples have different values of crystallinity than untreated chitin. If fresh ionic liquid (1 s) [Epyr][I], [Emim] [OAc], and [EMS][BFSI] was used, particle crystallinity was higher than that of untreated chitin while for the rest of the samples the crystallinity was lower.

It was interesting to notice that, for [Epyr][I], the crystalline phase of the regenerated chitin equaled $100 \%$ which means that chitin in crystal form was obtained. Change of the cation to [Emim] but with the same anion gave the lowest crystal phase content measured. Additionally an increase in crystallinity with decrease in the size of halide anion can be observed. The changes were not significant, but could be noticed. Similar situation can be suggested when the ionic liquids with organic acid anions are compared. Content of crystal phase was higher for [Emim] [OAc] than for [Emim][Lact].

Crystallinity of all chitin samples decreased if reused ionic liquids (4s) were applied. Significant decrease in the content of crystalline phase was observed especially for those ionic liquids that caused increase in crystallinity when fresh ILs were applied ([Epyr][I], [EMS][BFSI], and [Emim][OAc]). We assume that used ILs destroy intrachain bonds more significantly then fresh ILs. These changes in crystallinity could be caused either by disrupture of the crystal structure itself or changes in particle structure (surface corrugation, decomposition) connected with defects in crystal structure of particles. Increase in crystallinity in comparison to $1 \mathrm{~s}$ was observed for [Emim] [Br] and [Emim] [I] but content of crystalline phase was lower than for untreated particles.

3.5. Reusability of ILs. Possibility of reusing ionic liquid for a few times is an important factor that would decrease costs of ILs application on industrial scale and decrease the costs of environmental protection. The changes in ionic liquid composition were judged on the basis of FTIR spectra. FTIR spectra of fresh ionic liquids and regenerated after $4 \mathrm{~s}$ were compared. We assumed that FTIR spectra of ILs recovered after the last process ( $4 \mathrm{~s}$ ) should show any possible changes caused by decomposition/changes in structure as well as accumulation of impurities caused by chitin degradation; see Figure 4.

The analysis of FTIR spectra revealed the following results:

[Emim][Cl]. A less intense peak for $3369 \mathrm{~cm}^{-1}$, and additional small peak at $1089 \mathrm{~cm}^{-1}$ for regenerated ionic liquids was observed $(4 \mathrm{~s})$;

[Emim] $[\mathrm{Br}]$. Small increase in intensity of peak at $3400 \mathrm{~cm}^{-1}$, and significant increase in intensity of peaks at $1624 \mathrm{~cm}^{-1}, 1167 \mathrm{~cm}^{-1}$, and $645 \mathrm{~cm}^{-1}$; 


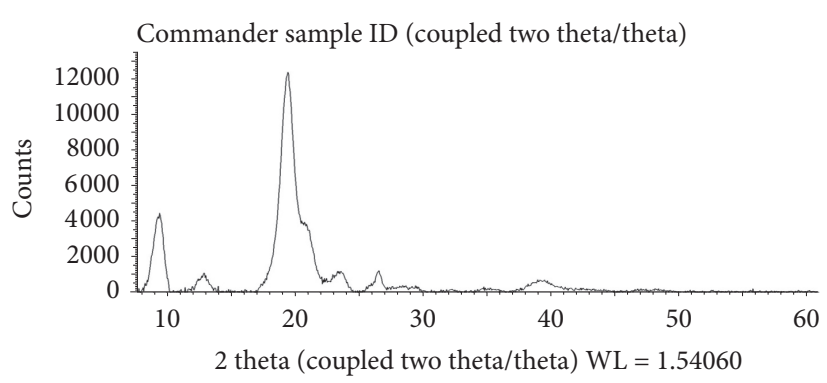

[Emim][OAc]

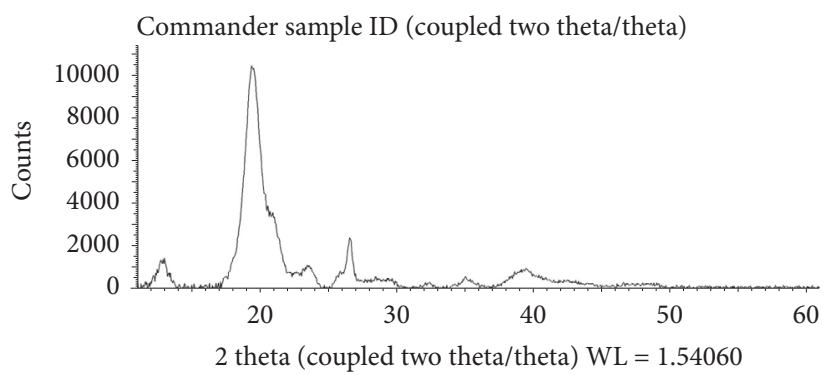

[Emim] [Cl]

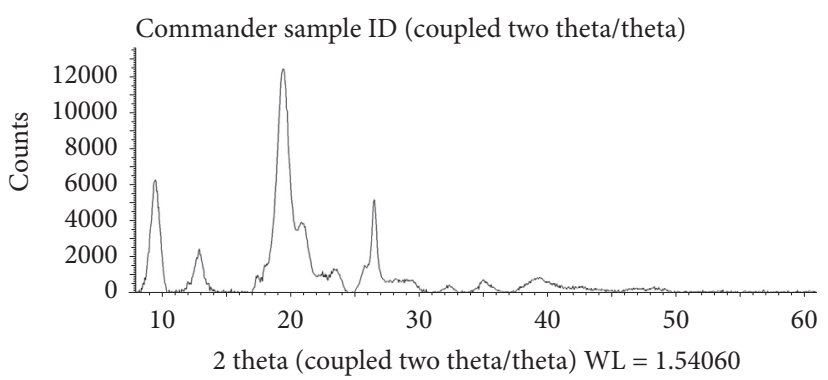

[Emim][I]

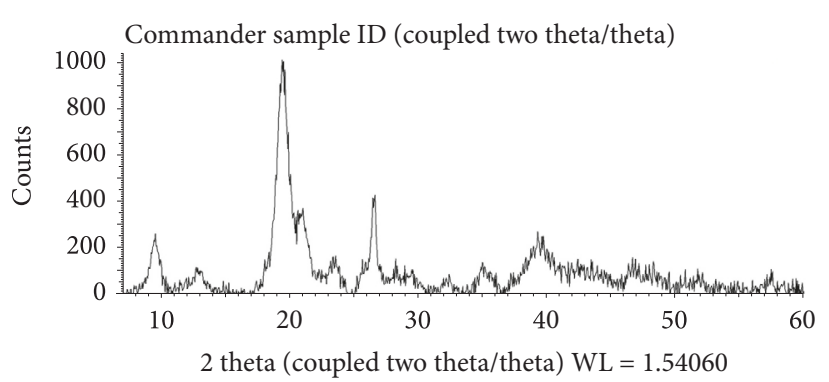

[Epyr][I]

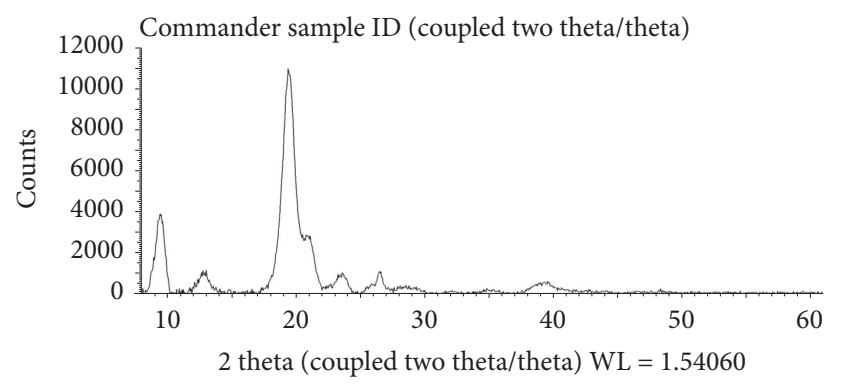

[Emim][Lact]

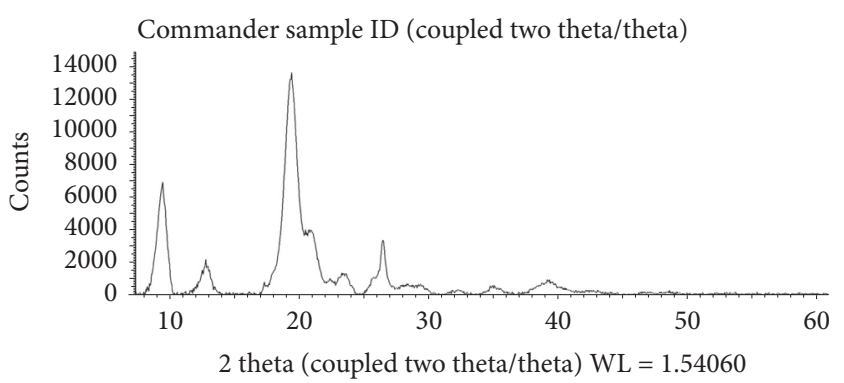

[Emim] [Br]

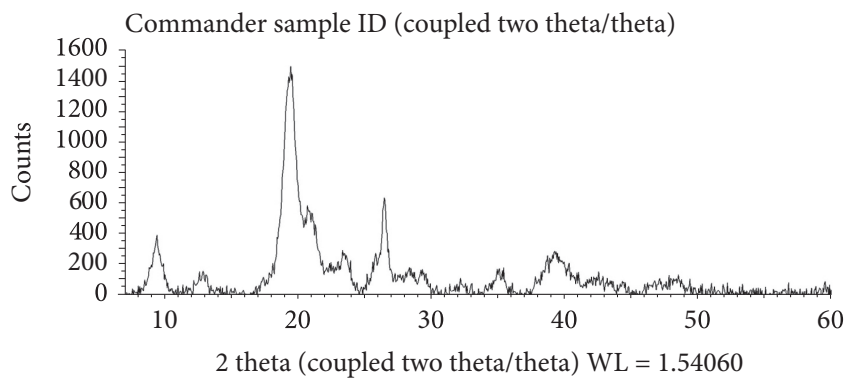

[EMS][BFSI]

FIGURE 3: XRD patterns of regenerated chitins regenerated in $4 \mathrm{~s}$ series.

[Emim][I]. Decrease in intensity of the peak at $3423 \mathrm{~cm}^{-1}$, and significant increase in intensity of peaks at $3077 \mathrm{~cm}^{-1}, 1568 \mathrm{~cm}^{-1}$, and $1165 \mathrm{~cm}^{-1}$, and for peaks in the range $567-895 \mathrm{~cm}^{-1}$;

[Epyr][I]. Decrease in intensity of the peak at $3446 \mathrm{~cm}^{-1}$, and significant increase in intensity of peaks at $1483 \mathrm{~cm}^{-1}, 1168 \mathrm{~cm}^{-1}, 1057 \mathrm{~cm}^{-1}, 779 \mathrm{~cm}^{-1}$, $677 \mathrm{~cm}^{-1}$, and $468 \mathrm{~cm}^{-1}$, two peaks at $1059 \mathrm{~cm}^{-1}$ and $1003 \mathrm{~cm}^{-1}$ disappeared in spectrum of recovered IL, peaks at $779 \mathrm{~cm}^{-1}, 644 \mathrm{~cm}^{-1}$, and $617 \mathrm{~cm}^{-1}$ appeared at spectrum of recovered IL, and peak at $1350 \mathrm{~cm}^{-1}$ split at two bands $\left(1369 \mathrm{~cm}^{-1}\right.$ and $\left.1350 \mathrm{~cm}^{-1}\right)$;

[Emim][Lact]. Increase in intensity of the peak at $3345 \mathrm{~cm}^{-1}$, decrease in intensity of peaks at $1589 \mathrm{~cm}^{-1}$, $1567 \mathrm{~cm}^{-1}$, and $1372 \mathrm{~cm}^{-1}$;

[Emim] [OAc]. A peak at $804 \mathrm{~cm}^{-1}$ in fresh IL shifted to $759 \mathrm{~cm}^{-1}$ for IL regenerated after the $4 \mathrm{~s}$. Additional wide peak appeared in the range $3190-3500 \mathrm{~cm}^{-1}$ which could be connected with presence of traces of water/ethanol; 

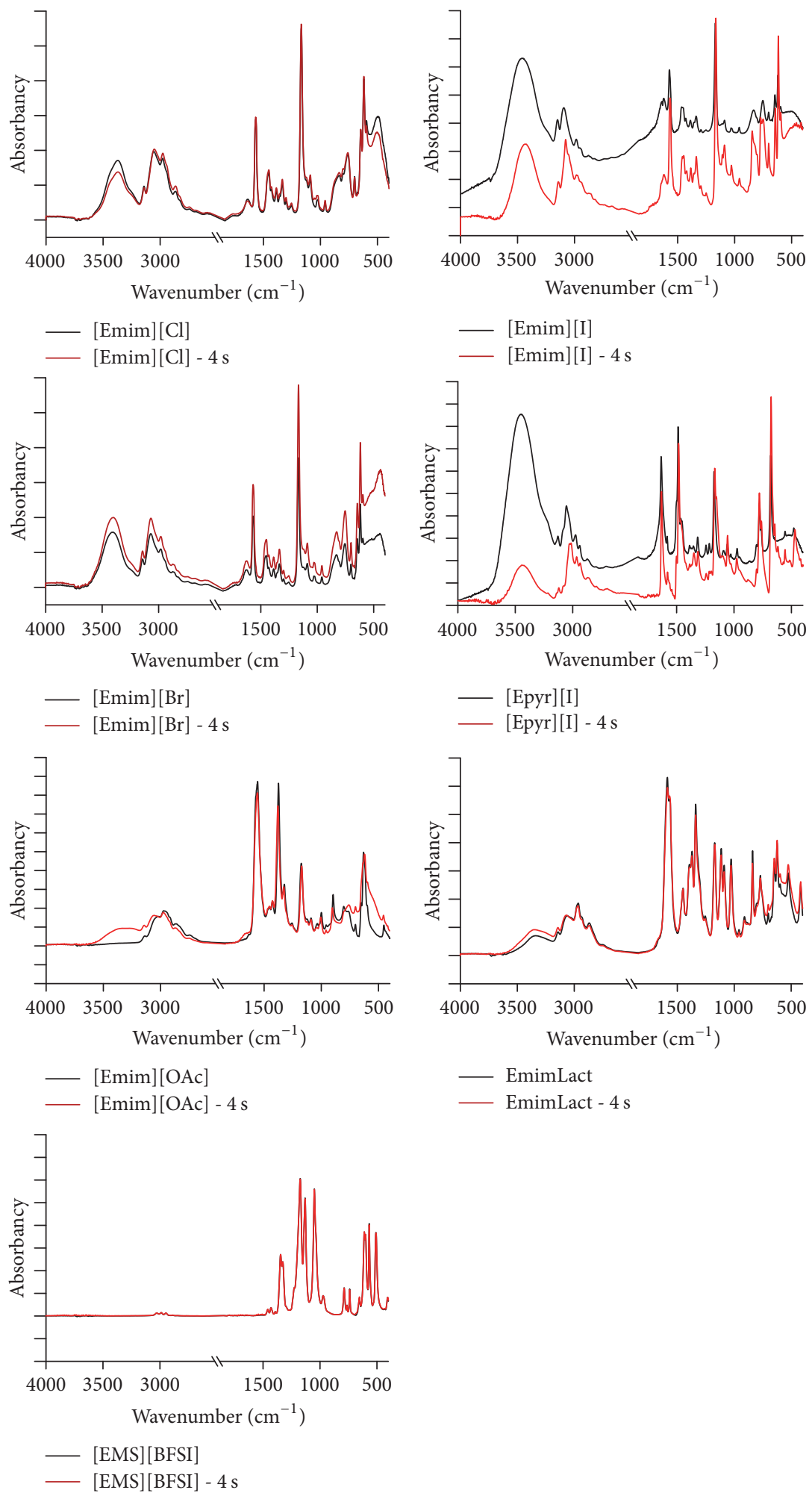

FIGURE 4: FTIR spectra of tested ionic liquids; black line: new ionic liquid, red: ionic liquids recovered after $4 \mathrm{~s}$.

[EMS][BFSI]. No changes of FTIR spectra have been observed between fresh IL and that regenerated after $4 \mathrm{s.}$

Changes in reused ionic liquids varied for each IL. For nearly all tested ionic liquids changes for wavenumber in the range 3200-3500 were observed, which could be caused by the presence of water/ethanol in samples (reused IL was either more dry or more "wet" than fresh one). Ionic liquids with an organic acid anion showed relatively smaller changes in spectra while significant changes were observed for ILs with 
halide anions (increase in peak intensity, disappearance of peaks, and appearance of additional peaks). That could be caused by changes in structure of ionic liquid resulting from the recovery process being carried out several times, or by washing out impurities present in fresh salts. It was also interesting to notice that there were no bands typical for $\alpha$-chitin or $\alpha$-chitin oligomers (amide I band at $1660 \mathrm{~cm}^{-1}$ and $1630 \mathrm{~cm}^{-1}$, amide II band at $1558 \mathrm{~cm}^{-1}$, and $\mathrm{CH}$ band at $895 \mathrm{~cm}^{-1}$ [11]) in all spectra of recovered ionic liquids. That suggests that chitin was not degraded during modification with ionic liquid to chitooligomers or $\mathrm{N}$-acetylglucosamine. As a fresh portion of chitin was used in each successive experiment in a series and after regeneration it was washed out several times and liquid was collected to evaporate etha$\mathrm{nol} /$ water, oligomers (if formed) would accumulate in the recovered ionic liquid and the signal typical for them would appear in the spectra. Lack of bands typical of chitin/chitooligomers/ $\mathrm{N}$-acetylglucosamine suggests that ionic liquids could cause degradation of chitin particles but not the hydrolysis of individual chains to oligomers.

\section{Discussion}

The data presented in this paper show the influence of seven commercially available ionic liquids containing ethyl substituents in the cation on solubility, particle size, particle size distribution, and crystallinity of chitin particles. Particles were recovered with water. The influence of reused ionic liquids on the morphology of chitin particles was also investigated. We have confirmed that ILs either modify the structure or particle size of chitin. We also proved that chitin can be entirely dissolved by a [Emim] [OAc]. The solution of chitin in IL at its concentration of $9 \% \mathrm{w} / \mathrm{w}$ was very viscous that caused problems in handling. Precipitation of ILs with water gave particles with much larger size probably due to the creation of new hydrogen bond networks between the chitin chains and formation of large agglomerates. Unfortunately, we have noticed that the ability to create agglomerates decreased with every next series of experiments. This could result from presence of water traces which could influence chitin solubility.

[Emim] [Lact] changed the chitin porosity but creation of new agglomerates could not be observed. Also chitin with lower crystallinity was obtained after contact with this ionic liquid.

[EMS][BFSI] was the next IL able to break hydrogen bonds. Solubility of chitin was very low (below 1\%), but decrease in particle size distribution was observed. The ability to destroy particle size increased with every next series of experiment. Surprisingly no changes in FTIR spectra of IL were noticed. That could result from washing out and evaporation of some impurities that could impede interaction between chitin and IL. This ionic liquid can be used for generation of chitin particles with desirable particle size and particle size range, but more experiments for evaluation of proper process conditions are needed.

For all ionic liquids with [Emim] cation and halide anion only structural changes in particles were observed. Although solubility of chitin was high (from 3\% for [Emim] [Cl] to $12 \%$ $[\mathrm{Emim}][\mathrm{Br}])$ the process was rather the gelation of particles than their dissolution with destruction of hydrogen bonds, as no changes in particle size distribution for precipitated chitin particles were noticed. ILs were able to increase the porosity of particles or their corrugation, but were not able to change its shape or size. It was also interesting to observe that the ability for modification of chitin particles depended on the number of regenerations of $([\mathrm{Emim}][\mathrm{Br}],[\mathrm{Emim}][\mathrm{I}])$ and was probably strongly dependent on the presence of water traces in the ionic liquid. This proves the importance of the drying process on the possibility of reusing ionic liquids for modification of chitin. Although these ionic liquids did not modify the size of particles, they can be used for structure modification (porosity, corrugation) of particles.

On changing the cation from [Emim] to [Epyr] quite different IL-chitin interactions were observed. First of all chitin solidified during dissolution in [Epyr][I], and after recovery particles with high (nearly 100\%) crystallinity were obtained, with slightly modified surfaces. Solidification and high crystallinity suggest that [Epyr][I] can change the amorphous structure of chitin particles into a crystalline one, changing random arrangements of chitin chains into ordered ones. These ionic liquids can be than applied for preparation of chitin crystals.

Presented data shows several interesting observations on chitin-ionic liquids interactions that have not been reported so far. Application of ILs for modification of chitin particles to get a good carrier for enzymes will be the subject of our further investigations.

\section{Conflicts of Interest}

The authors declare that they have no conflicts of interest.

\section{Acknowledgments}

This work has been supported by the budget sources for The National Centre for Science (Poland), Grant no. DEC2013/09/B/ST8/00144. The authors would like to thank Merck $\mathrm{KGaA}$ for their kind donation of [Emim] [Cl] ionic liquid.

\section{References}

[1] M. Hanley, J. M. Green III, W. A. Henderson, D. Fox, H. C. De Long, and P. C. Trulove, "Amino acid based ionic liquids: solvents for improved biopolymer dissolution," in Proceedings of the 210th Meeting of the Electrochemical Society, Conference Materials, Abstract 2018, pp. 41-48, Cancun, Mexico, 2006.

[2] Y. Qin, X. Lu, N. Sun, and R. D. Rogers, "Dissolution or extraction of crustacean shells using ionic liquids to obtain high molecular weight purified chitin and direct production of chitin films and fibers," Green Chemistry, vol. 12, no. 6, pp. 968-971, 2010.

[3] M. M. Jaworska and A. Gorak, "Modification of chitin particles with chloride ionic liquids," Materials Letters, vol. 164, pp. 341343, 2016.

[4] P. S. Barber, C. S. Griggs, J. R. Bonner, and R. D. Rogers, "Electrospinning of chitin nanofibers directly from an ionic liquid extract of shrimp shells," Green Chemistry, vol. 15, no. 3, pp. 601-607, 2013. 
[5] P. S. Barber, S. P. Kelley, C. S. Griggs, S. Wallace, and R. D. Rogers, "Surface modification of ionic liquid-spun chitin fibers for the extraction of uranium from seawater: seeking the strength of chitin and the chemical functionality of chitosan," Green Chemistry, vol. 16, no. 4, pp. 1828-1836, 2014.

[6] K. Mundsinger, A. Müller, R. Beyer, F. Hermanutz, and M. R. Buchmeiser, "Multifilament cellulose/chitin blend yarn spun from ionic liquids," Carbohydrate Polymers, vol. 131, pp. 34-40, 2015.

[7] N. Singh, K. K. K. Koziol, J. Chen et al., "Ionic liquids-based processing of electrically conducting chitin nanocomposite scaffolds for stem cell growth," Green Chemistry, vol. 15, no. 5, pp. 1192-1202, 2013.

[8] J. L. Shamshina, G. Gurau, L. E. Block et al., "Chitin-calcium alginate composite fibers for wound care dressings spun from ionic liquid solution," Journal of Materials Chemistry B, vol. 2, no. 25, pp. 3924-3936, 2014.

[9] P. S. Barber, C. S. Griggs, G. Gurau et al., "Coagulation of chitin and cellulose from 1-ethyl-3-methylimidazolium acetate ionicliquid solutions using carbon dioxide," Angewandte ChemieInternational Edition, vol. 52, no. 47, pp. 12350-12353, 2013.

[10] Y. Chen, X. Sun, C. Yan, Y. Cao, and T. Mu, "The dynamic process of atmospheric water sorption in [EMIM][Ac] and mixtures of [EMIM] [Ac] with biopolymers and $\mathrm{CO} 2$ capture in these systems," The Journal of Physical Chemistry. B, vol. 118, no. 39, pp. 11523-11536, 2014.

[11] J. Kumirska, M. Czerwicka, Z. Kaczyński et al., "Application of spectroscopic methods for structural analysis of chitin and chitosan," Marine Drugs, vol. 8, no. 5, pp. 1567-1636, 2010. 

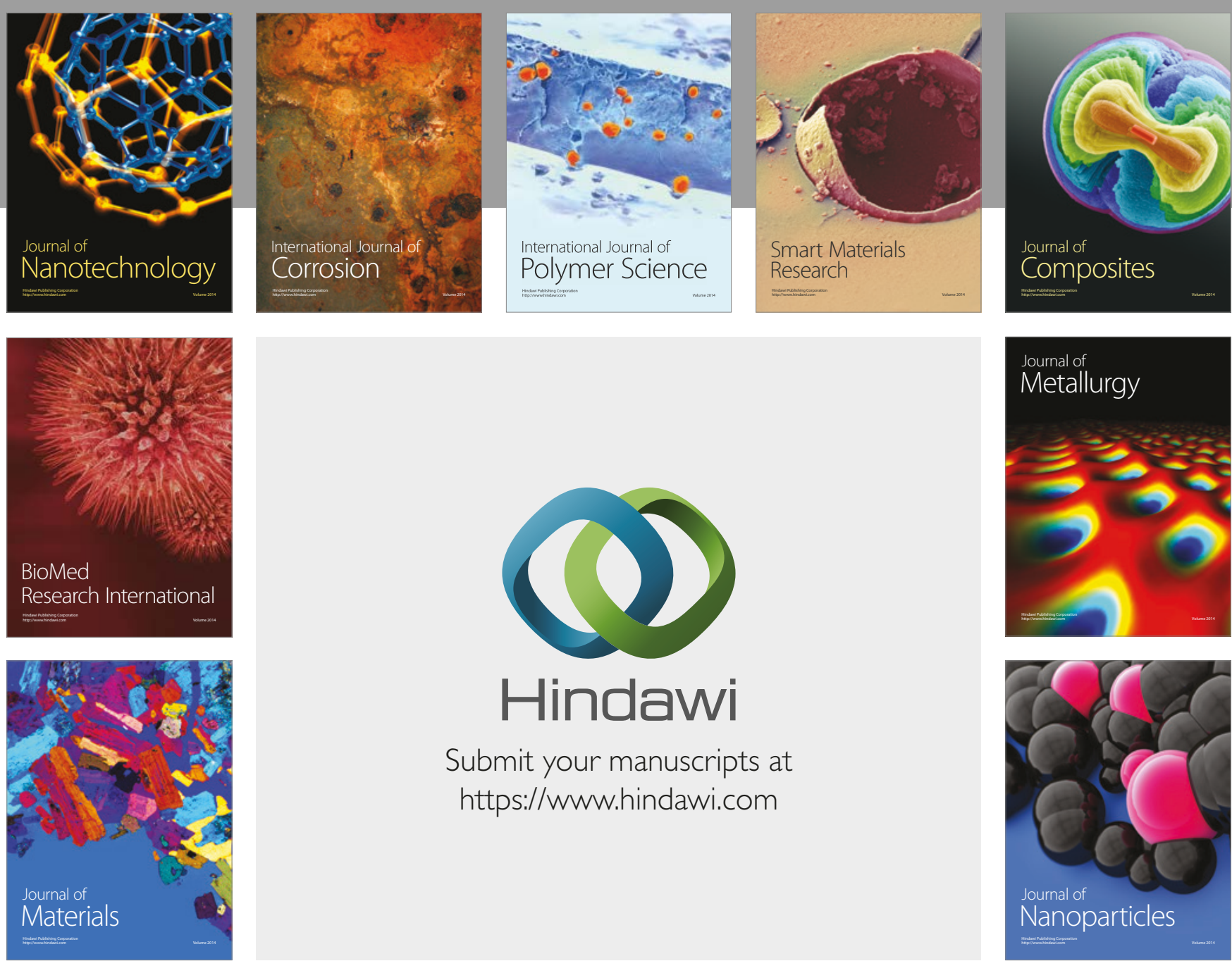

\section{Hindawi}

Submit your manuscripts at

https://www.hindawi.com
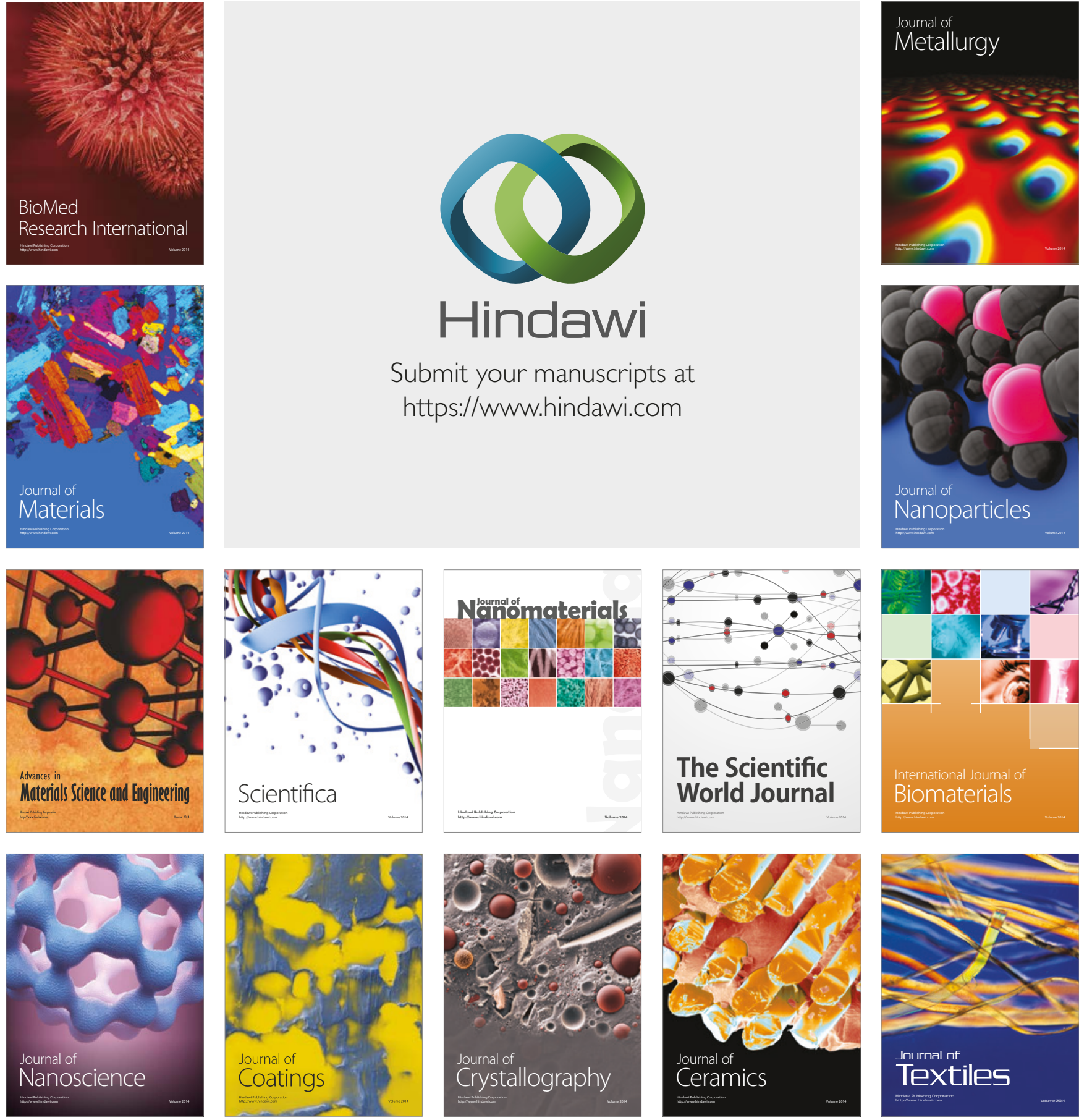

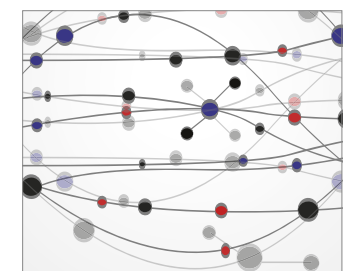

The Scientific World Journal
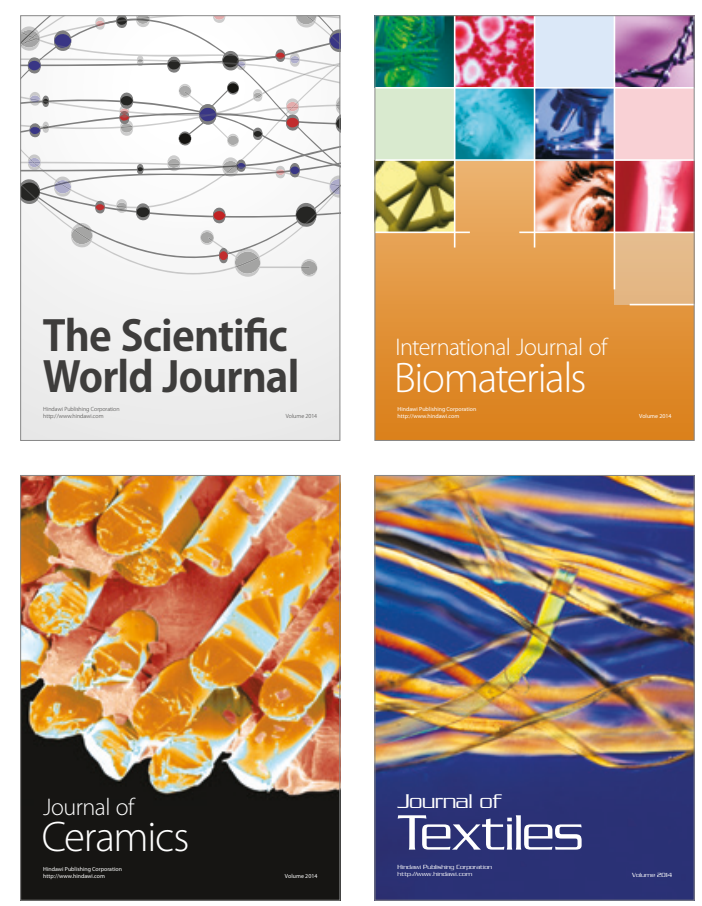